\title{
Emergency-to-Elective Surgery Ratio: A Global Indicator of Access to Surgical Care
}

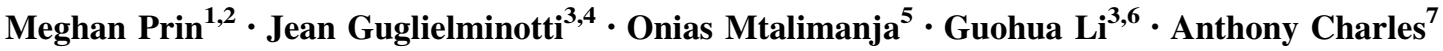

Published online: 21 December 2017

\begin{abstract}
Background Surgical care is essential to health systems but remains a challenge for low- and middle-income countries (LMICs). Current metrics to assess access and delivery of surgical care focus on the structural components of surgery and are not readily applicable to all settings. This study assesses a new metric for surgical care access and delivery, the ratio of emergent surgery to elective surgery (Ee ratio), which represents the number of emergency surgeries performed for every 100 elective surgeries.

Methods A systematic search of PubMed and Medline was conducted for studies describing surgical volume and acuity published between 2006 and 2016. The relationship between Ee ratio and three national indicators (gross domestic product, per capital healthcare spending, and physician density) was analyzed using weighted Pearson correlation coefficients $\left(r_{\mathrm{w}}\right)$ and linear regression models.

Results A total of 29 studies with 33 datasets were included for analyses. The median Ee ratio was 14.6 (IQR 5.5-62.6), with a range from 1.6 to 557.4. For countries in sub-Saharan Africa the median value was 62.6 (IQR 17.8-111.0), compared to 9.4 (IQR 3.4-13.4) for the United States and 5.5 (IQR 4.4-10.1) for European countries. In multivariable linear regression, the per capita healthcare spending was inversely associated with the Ee ratio, with a 63-point decrease in the Ee ratio for each 1 point increase in the log of the per capita healthcare spending (regression coefficient $\beta=-63.2 ; 95 \% \mathrm{CI}-119.6$ to $-6.9 ; P=0.036$ ).

Conclusions The Ee ratio appears to be a simple and valid indicator of access to available surgical care. Global health efforts may focus on investment in low-resource settings to improve access to available surgical care.
\end{abstract}

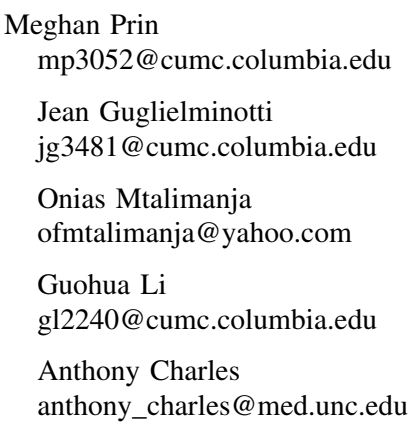

1 Department of Anesthesiology and Critical Care, Columbia University College of Physicians and Surgeons, New York, NY, USA
2 Department of Anesthesiology and Critical Care, Columbia University Medical Center, 622 West 168th Street, PH-505, New York, NY 10032, USA

3 Department of Anesthesiology, Columbia University College of Physicians and Surgeons, New York, NY, USA

4 INSERM, UMR 1137, IAME, 16 rue Henri Huchard, 75018 Paris, France

5 Department of Anaesthesiology, Kamuzu Central Hospital, Lilongwe, Malawi

6 Department of Epidemiology, Columbia University Mailman School of Public Health, New York, NY, USA

7 Department of Surgery, University of North Carolina at Chapel Hill, Chapel Hill, NC, USA 


\section{Introduction}

Surgery is an essential component of global health and an integral and essential component of a properly functioning health system [1]. However, the provision of timely and quality surgical care remains a challenge for many lowand middle-income countries (LMICs), particularly in subSaharan Africa [2-5]. With an estimated 30\% of the global burden of disease due to surgical conditions [6], it is now widely recognized that there are enormous disparities in access to life-saving and disability-preventing surgical services, particularly for rural and/or marginalized populations $[7,8]$.

Determinants of surgical access begin with the availability of an adequate surgical workforce within a healthcare system that is equipped to deliver surgical care with the necessary infrastructure at the district (general) and central (tertiary) hospitals, respectively. Patient-related determinants of surgical access include socioeconomic status, educational attainment level, sex, geographic proximity to healthcare facilities, and sociocultural norms regarding medical care [5, 9]. The role of government and healthcare system maturity can also not be underestimated, particularly in resource-poor settings where there are less private options in the healthcare market. Healthcare must be affordable to the general public, or this may affect patients' decisions regarding the timeliness of presentation to care.

Available access to safe surgical care is essential to several of the Millennium Development Goals established by the United Nations in 2000, namely the reduction in child mortality and the improvement of maternal health. Achievement of these goals has been challenging and varied worldwide. This has been most prominent in sub-Saharan Africa. Disparities in achieving the Millennium Development Goals contributed to a "call to action" in surgical epidemiology by the World Health Organization (WHO) in 2012 [10], and the more recent Millennium Sustainable Goals recognize the importance of surgical care delivery by acknowledging the emerging prevalence of non-communicable diseases. Additionally, the Safe Surgery Saves Lives Initiative of the WHO Patient Safety Program developed standardized public health indicators for measuring and monitoring surgical services at a national level [11].

Current metrics to evaluate surgical care are largely focused on the structural capacity for surgery, but overlook patients' access to available care. Timely access to available care is the keystone in the cascade of medical treatment. This is particularly important for surgical conditions, in which early elective care is safer and simpler than urgent or emergent procedures [12-14]. Emergency surgery often occurs as a result of delays in presentation to care $[2,3]$. Increasing the proportion of elective surgery (i.e., intervening on surgical disease early in its clinical course) in a healthcare system may be an important first step to reducing the need for emergency surgery and reducing preventable mortality associated with surgical disease. We therefore propose the use of an emergency-to-elective (Ee) surgery ratio as a new metric to reflect access to available surgical care. The purpose of this study is to evaluate the currently available data describing the proportion of emergency and elective surgeries conducted worldwide, and how the Ee ratio in various regions is associated with national healthcare system indicators.

\section{Methods}

PubMed and Medline were searched according to the Preferred Reporting Items for Systematic Reviews and Meta-Analyses (PRISMA) guidelines [15] from January 1, 2006, to November 14, 2016, for studies, reports, or datasets describing surgical volume and acuity at the hospital, regional, national, or international level. This protocol was not registered. Manuscripts were excluded if they exclusively focused on elective surgeries (e.g., cosmetic surgery) or if they did not include the relevant data (e.g., sample size). The search string is given in "Appendix 1" and the study selection in "Appendix 2". The last search was performed on November 14, 2016. Studies were included if they included descriptive data of the number of elective and emergent surgeries performed in a given time period. The reference lists within eligible studies were searched to identify additional eligible studies. Unpublished data from the authors' research site in Malawi were included. The following data were extracted from each report: (1) general characteristics of the study (e.g., geographic location, years of inclusion) and (2) characteristics of the surgical cohort and acuity (emergency vs. elective). Because the objective was to identify descriptive datasets, a quality assessment was not performed.

Elective surgery was defined as a procedure that is scheduled in advance and not immediately life threatening and may be planned within weeks or months. Urgent surgery was defined as a planned procedure that should be performed within hours or days of the decision to operate. Emergency surgery was defined as a procedure that should be performed as soon as possible, ideally within $24 \mathrm{~h}$, and which may be life saving. For this study, the urgent and emergent surgery categories were combined. The emergency/elective (Ee) ratio was calculated by dividing the number of emergent surgeries by the number of elective surgeries, and multiplying by 100 , so that it can be interpreted as the number of emergent surgeries performed for every 100 elective surgeries. 
We calculated the Ee ratio for each dataset and compared the values across different geographic regions using the Kruskal-Wallis test. We looked for a relationship between the Ee ratio and three national indicators: the gross domestic product (GDP), the per capita healthcare spending, and the physician workforce supply per 1000 population. These data were obtained from the World Bank based on data corresponding or closest to the study year. Both were converted to US dollars at market exchange rates. For single-country multiyear studies, the median spending value for all the years was used. For multicountry studies, a population-weighted mean per capita healthcare spending for all countries in that time period was used. For the data from Mèdecins Sans Frontières (MSF) spanning 2011-2013, population-weighted mean healthcare spending data from 2012 were applied.

To examine the association between the three indicators and the Ee ratio, we first calculated the weighted Pearson correlation coefficient $\left(r_{\mathrm{w}}\right)$ between the Ee ratio and each indicator, using the inverse of the log of the sample size as weight. We then used weighted univariable linear regression to assess the relationship between the indicators (expressed in logarithm) and the Ee ratio, using the inverse of the $\log$ of the sample size as weight. Because of a high correlation between the three indicators, we performed a weighted multivariable linear regression. We conducted a sensitivity analysis excluding the data from MSF given the uncertainty in the accuracy of the associated estimates for these conflict zones and the fact that this dataset was an influential outlier. Statistical analysis was performed using Stata/SE 14.2 (StataCorp, College Station, TX). Data are presented as median [interquartile range (IQR)]. Significance was set at 0.05 for all analyses.

\section{Results}

A total of 28 citations met the inclusion criteria, and, including primary data from the authors' research site, 29 citations containing 33 datasets were included in the final analysis. The included studies were published from 2006 to 2016, and included data collected from 1989 to 2016. International data were available in two citations, national data in nine, regional data in four, and hospital data in 14 citations (Table 1).

\section{Emergency/elective (Ee) ratio}

The median Ee ratio was 14.6 (interquartile range (IQR) 5.5-62.6), with a range from 1.6 (Sierra Leone, all case types) to 557.4 (international data from MSF). The median Ee ratio varied across geographic regions. For countries in sub-Saharan Africa the median value was 62.6 (IQR
17.8-111.0), compared to 9.4 (IQR 3.4-13.4) for the United States and 5.5 (IQR 4.4-10.1) for European countries $(P=0.015$, Fig. 1$)$.

In the main analysis, there was a statistically significant negative correlation between Ee ratio and per capita healthcare spending $\left(r_{\mathrm{w}}=-0.33 ; 95 \% \mathrm{CI}-0.47\right.$ to -0.19 ; $P<0.001)$, physician workforce $\left(r_{\mathrm{w}}=-0.34 ; 95 \%\right.$ CI -0.50 to $-0.19 ; P<0.001)$, and GDP $\left(r_{\mathrm{w}}=-0.25,95 \%\right.$ CI -0.37 to $-0.13 ; P<0.001)$. In the univariable weighted linear regression, a statistically significant inverse relationship was observed between the Ee ratio and per capita healthcare spending (coefficient $\beta=-18.8 ; 95 \%$ CI -34.0 to $-3.6 ; P=0.021$ ) but not with the physician workforce (coefficient $\beta=-15.7 ; 95 \%$ CI -32.7 to 1.3 ; $P=0.080$ ) or the GDP (coefficient $\beta=-10.5 ; 95 \%$ CI -22.0 to $1.1 ; P=0.085$ ).

A statistically significant correlation was observed between the per capita healthcare spending and the physician workforce $(r=0.80 ; 95 \%$ CI $0.64-0.90 ; P<0.001)$ and per capita healthcare spending and the GDP $(r=0.79$; 95\% CI $0.61-0.89 ; P<0.001)$. In the multivariable weighted linear regression including the three indicators, the per capita healthcare spending remained significantly associated with the Ee ratio (coefficient $\beta=-63.2 ; 95 \%$ CI -119.6 to $-6.9 ; P=0.036$ ) (Table 2). In other words, every $1-\log$ increase in the per capita healthcare spending was associated with a 63-point decrease in the Ee ratio (Fig. 2). The results remained virtually unchanged in the sensitivity analysis excluding the MSF study (data not shown).

\section{Discussion}

This study presents the Ee ratio as a new metric for access to surgical care and demonstrates that it correlates with per capita healthcare spending. This confirms its use as an indicator of healthcare systems investment. The Ee ratio is easily applied in assessing surgical services at the local, regional, national, and international level and can be used to compare health systems at these levels. The Ee ratio is novel in its applicability to all patient populations, and its reflection of patients' ability to access needed surgical care in a timely fashion.

Ee ratio is not only a direct measure of access to care but also an indirect indicator of anticipated perioperative mortality risk. A retrospective analysis of 298,772 patients from the American College of Surgeons National Surgical Quality Improvement Program (NSQIP) demonstrated that emergency status conveyed an adjusted odds ratio (OR) for mortality of $2.54(p<0.001)$ [12]. Similarly, an analysis of almost 3 million surgical cases performed in the United States between 2010 and 2014 using the National 
Table 1 Emergency-to-elective surgery ratios in selected countries

\begin{tabular}{|c|c|c|c|c|c|}
\hline Source & Year(s) & $\begin{array}{l}\text { Procedures } \\
\text { evaluated }\end{array}$ & $\begin{array}{l}\text { Emergency, } \\
(n)\end{array}$ & $\begin{array}{l}\text { Elective, } \\
(n)\end{array}$ & $\begin{array}{l}\text { Emergency/elective } \\
\text { ratio }\end{array}$ \\
\hline \multicolumn{6}{|l|}{ International-level data } \\
\hline EuSOS Group, 28 European Nations [23] ${ }^{\mathrm{a}}$ & 2011 & $\begin{array}{l}\text { Non-cardiac } \\
\text { inpatient } \\
\text { surgery }\end{array}$ & 11,480 & 35,049 & 32.8 \\
\hline $\begin{array}{l}\text { Medecins Sans Frontieres General Surgery Projects of the } \\
\text { Democratic Republic of the Congo, Central African } \\
\text { Republic, and South Sudan [14] }\end{array}$ & 2011-2013 & All & 7803 & 1400 & 557.4 \\
\hline \multicolumn{6}{|l|}{ National-level data } \\
\hline Australia, National Health Services Statistics [24] & 2013-2014 & All & 304,741 & $2,080,152$ & 14.6 \\
\hline $\begin{array}{l}\text { Denmark, National Hernia Database and National Hospital } \\
\text { Registry [25] }\end{array}$ & 2003-2008 & $\begin{array}{l}\text { Inguinal hernia } \\
\text { repair }\end{array}$ & 1829 & 49,404 & 3.7 \\
\hline Sweden, Swedish Hernia Register [26] & $1992-2005$ & $\begin{array}{l}\text { Inguinal and } \\
\text { femoral } \\
\text { hernia repair }\end{array}$ & 6348 & 101,490 & 6.3 \\
\hline Sweden, Swedish Hernia Register [27] & 1998-2009 & $\begin{array}{l}\text { Inguinal hernia } \\
\text { repair }\end{array}$ & 7089 & 143,425 & 4.9 \\
\hline $\begin{array}{l}\text { United States, National Anesthesia Clinical Outcomes } \\
\text { Registry [13] }\end{array}$ & 2010-2014 & All & 82,324 & $2,647,035$ & 3.1 \\
\hline United States, National Inpatient Sample [28] & 2004-2008 & $\begin{array}{l}\text { Spinal fusion } \\
\text { surgery }\end{array}$ & 45,953 & 310,904 & 14.8 \\
\hline $\begin{array}{l}\text { United States, National Surgical Quality Improvement } \\
\text { Program [29] }\end{array}$ & 2005-2008 & All & 67,445 & 406,174 & 16.6 \\
\hline $\begin{array}{l}\text { United States, National Surgical Quality Improvement } \\
\text { Program [30] }\end{array}$ & 2010 & Not specified & 35,908 & 276,332 & 12.9 \\
\hline $\begin{array}{l}\text { United States, Society of American Gastrointestinal and } \\
\text { Endoscopic Surgeons Registry [31] }\end{array}$ & 1995-2005 & $\begin{array}{l}\text { Inguinal hernia } \\
\text { repair }\end{array}$ & 46 & 1543 & 2.9 \\
\hline \multicolumn{6}{|l|}{ Regional-level data } \\
\hline Italy, Emilia-Romagna Hospitals [32] & 2000-2009 & $\begin{array}{l}\text { Inguinal hernia } \\
\text { repair }\end{array}$ & 6653 & 120,260 & 5.5 \\
\hline $\begin{array}{l}\text { South Africa, South African Surgical Outcomes Investigators } \\
\text { [33] }\end{array}$ & 2014 & $\begin{array}{l}\text { Non-cardiac } \\
\text { inpatient } \\
\text { surgery }\end{array}$ & 2120 & 1795 & 118.1 \\
\hline United States, Michigan Surgery Quality Collaborative [34] & 2005-2010 & $\begin{array}{l}\text { General non- } \\
\text { cardiac } \\
\text { surgery }\end{array}$ & 21,086 & 169,740 & 12.4 \\
\hline $\begin{array}{l}\text { United States, Rochester, Minnesota, Epidemiology Project } \\
\text { [35] }\end{array}$ & 1989-2008 & $\begin{array}{l}\text { Inguinal hernia } \\
\text { repair }\end{array}$ & 136 & 3890 & 3.5 \\
\hline \multicolumn{6}{|l|}{ Hospital-level data } \\
\hline $\begin{array}{l}\text { Brazil, University Hospital of the Universidade Federale de } \\
\text { Sao Paulo [36] }\end{array}$ & 2011-2012 & $\begin{array}{l}\text { All weekday } \\
\text { procedures }\end{array}$ & 3760 & 4600 & 81.7 \\
\hline Ghana, Komfo Anokye Teaching Hospital [37] & 1998-2007 & $\begin{array}{l}\text { External } \\
\text { hernia repair }\end{array}$ & 1294 & 1212 & 106.7 \\
\hline Japan, Kawasaki Medical School Hospital [38] & 2010-2014 & $\begin{array}{l}\text { All inpatient } \\
\text { procedures }\end{array}$ & 2304 & 15,421 & 14.9 \\
\hline Malawi, Kamuzu Central Hospital [39] & 2004-2007 & All & 5243 & 6908 & 75.9 \\
\hline Malawi, Kamuzu Central Hospital [39] & 2015-2016 & All & 2553 & 2216 & 115.2 \\
\hline Malawi, Kamuzu Central Hospital [19] & 2009 & $\begin{array}{l}\text { Inguinal hernia } \\
\text { repair }\end{array}$ & 88 & 131 & 67.2 \\
\hline Mozambique, Hospital Rural de Chókwè [40] & 2015 & All & 88 & 30 & 293.3 \\
\hline Rwanda, Butaro District Hospital [41] & 2013 & $\begin{array}{l}\text { Non-obstetric } \\
\text { surgery }\end{array}$ & 24 & 377 & 6.4 \\
\hline Rwanda, Rwinkwavu District Hospital [41] & 2013 & $\begin{array}{l}\text { Non-obstetric } \\
\text { surgery }\end{array}$ & 8 & 38 & 21.1 \\
\hline
\end{tabular}


Table 1 continued

\begin{tabular}{|c|c|c|c|c|c|}
\hline Source & Year(s) & $\begin{array}{l}\text { Procedures } \\
\text { evaluated }\end{array}$ & $\begin{array}{l}\text { Emergency, } \\
(n)\end{array}$ & $\begin{array}{l}\text { Elective, } \\
(n)\end{array}$ & $\begin{array}{l}\text { Emergency/elective } \\
\text { ratio }\end{array}$ \\
\hline Rwanda, Kirehe District Hospital [41] & 2013 & $\begin{array}{l}\text { Non-obstetric } \\
\text { surgery }\end{array}$ & 4 & 86 & 4.7 \\
\hline Sierra Leone, Connaught Hospital [42] & 2012-2013 & All & 8 & 496 & 1.6 \\
\hline Sierra Leone, Princess Christian Maternity Hospital [42] & 2012-2013 & $\begin{array}{l}\text { Obstetrics and } \\
\text { gynecology }\end{array}$ & 66 & 184 & 35.9 \\
\hline Tanzania, Bugando Medical Centre [43] & 2010-2012 & $\begin{array}{l}\text { Inguinal hernia } \\
\text { repair }\end{array}$ & 174 & 278 & 62.6 \\
\hline Turkey, Ankara Diskapi Education and Research Hospital [44] & 2005-2009 & $\begin{array}{l}\text { Inguinal hernia } \\
\text { repair }\end{array}$ & 84 & 601 & 13.9 \\
\hline Uganda, Iganga General and Buluba Mission Hospitals [45] & 2011 & All & 1581 & 2701 & 58.5 \\
\hline Uganda, Mbarara Regional Referral Hospital [46] & $2008-2011$ & All & 810 & 5536 & 14.6 \\
\hline $\begin{array}{l}\text { United Kingdom, Sheffield Teaching Hospitals NHS Trust } \\
\text { [47] }\end{array}$ & 2005-2007 & Inguinal hernia & 135 & 3464 & 3.9 \\
\hline United States, Boston Veteran Affairs Healthcare System [48] & $2001-2009$ & $\begin{array}{l}\text { Inguinal hernia } \\
\text { repair }\end{array}$ & 63 & 971 & 6.5 \\
\hline
\end{tabular}

${ }^{a}$ EuSOS countries include Belgium, Croatia, Cyprus, Czech Republic, Denmark, Estonia, Finland, France, Germany, Greece, Hungary, Iceland, Ireland, Italy, Latvia, Lithuania, The Netherlands, Norway, Poland, Portugal, Romania, Serbia, Slovakia, Slovenia, Spain, Sweden, Switzerland, and the United Kingdom

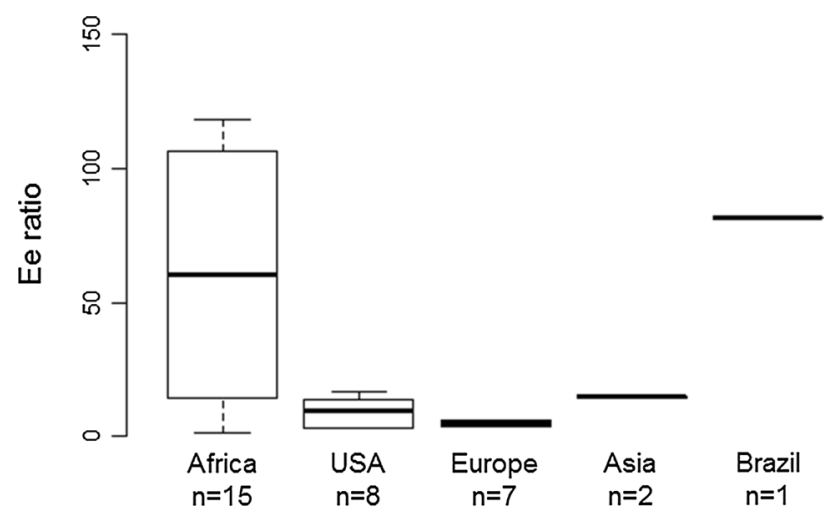

Fig. 1 Boxplot of the Ee ratio according to the geographic area. The horizontal thick line indicates the median, the lower and upper limits of the box the 25th and 75th percentiles, and $n$ the number of studies

Anesthesia Clinical Outcomes Registry showed that emergency status conferred an adjusted odds ratio for mortality of 2.70 [13]. The mortality risk associated with emergency surgery may be most obvious in the setting of military conflict; the adjusted odds ratio for mortality associated with emergency surgery in three African conflict zones ranged from 2.17 to 2.76 [14]. The etiology of excess mortality associated with emergency surgery has not been rigorously evaluated, but may be due to delayed presentation, lack of preoperative patient preparation, and absence of prepared staff and equipment. In this capacity, Ee ratio serves as a metric for surgical safety at the population and healthcare system level.

There is significant worldwide variation in the Ee ratio, with particularly large differences between high-income and low-income countries. This is consistent with the fact that low-income nations carry a disproportionate share of the global burden of surgical illness and are unable to invest in improving surgical services. However, given the heterogeneity of these data, it is not obvious what Ee ratio may be considered an acceptable goal. The ultimate objective of the Ee ratio is not to determine a universal standard but rather to set a benchmark across a national health system that reflects not the exact volume or case mix, but rather the way in which a system can provide care as a whole. Emergency surgery is not completely avoidable, and every system must include surge capacity to accommodate for trauma, violence, and natural disasters. These data demonstrate a global median Ee ratio of 14.6, while in high-income nations of North American and Europe the median Ee ratios is 9.4 and 5.5, respectively. The MSF data provide useful context for an Ee ratio in a region with active conflict and complete reliance on external aid: 557.4. The ideal Ee ratio is likely close to 5.5, that achieved by European countries, but this may be unattainable for low-resource healthcare systems disproportionately affected by high disease burden and low provider density. We recommend that LMICs plan healthcare investments with the goal of reducing their Ee ratio, with 
Table 2 Multivariable weighted linear regression model examining the relationship between the three indicators (expressed in a log form) and the Ee ratio

\begin{tabular}{lcll} 
& Beta coefficient & $95 \%$ confidence interval & $P$ value \\
\hline Intercept & 410.3 & 60.6 to 759.9 & 0.029 \\
Per capita healthcare spending & -63.2 & -119.6 to -6.9 & 0.036 \\
Physician supply per 1000 population & 12.1 & -17.4 to 41.6 & 0.427 \\
Gross domestic product & 32.9 & -20.2 to 86.2 & 0.234 \\
\hline
\end{tabular}

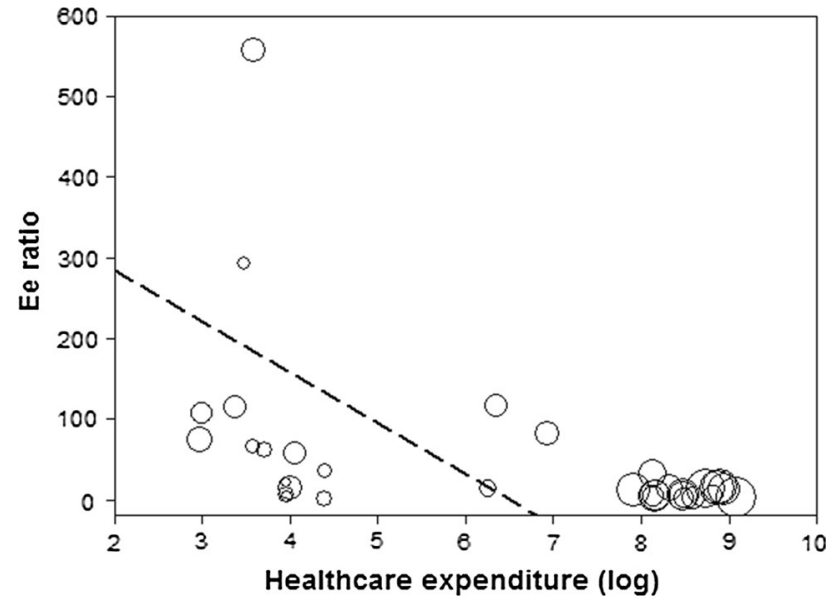

Fig. 2 Relationship between the Ee ratio and the per capita healthcare expenditure (in a $\log$ form). Each circle represents one study, and the diameter of the circle is proportional to the weight of that study in the analysis. The dashed line is the regression line from the weighted multivariable regression model. The relation between the Ee ratio and the per capita healthcare expenditure is significant with a decrease in the Ee ratio as the expenditure increases (slope $-63.2 ; 95 \% \mathrm{CI}-119.6$ to $-6.9 ; P=0.036)$

the understanding that there may be varying success in the short term. Stepwise investments in surgical care may reveal the most efficient systems changes.

It is also notable that the majority of data from lowresource settings (e.g., sub-Saharan Africa) were at the hospital level, while national datasets were primarily from high-income countries. International consensus will rely on (1) the development of comprehensive datasets, particularly multicenter databases representing low-resource settings, (2) discussions of how sociocultural norms affect patients' access to and timeliness of care, and (3) controlling for regions with endemic violence.

The recent call to action by the WHO has brought renewed vigor to surgical epidemiology, and several other metrics have been proposed for evaluating surgical care. The standardized national-level indicators put forth by the
WHO are (1) number of operating rooms, (2) number of operations performed, (3) number of accredited surgeons, (4) number of accredited anesthesia professionals, (5) dayof-surgery death ratio, and (6) postoperative in-hospital death ratio. While valuable from a development standpoint in quantifying and benchmarking national surgical infrastructure, these metrics do not reflect the realities of healthcare faced by many LMICs, where physician-extenders frequently provide surgical care [16]. It is imperative that any surgical care metric allows for this difference in workforce profile. These indicators also provide no context for mortality data. For example, one could not deduce from a day-of-surgery death ratio if the root cause was delayed presentation to care, emergency status, lack of equipment, lack of providers, or adverse treatment effects.

The perioperative mortality rate (POMR) has also been proposed as a global indicator of access to safe surgical care. However, the POMR is more directly influenced by intraoperative and postoperative care than patients' ability to access available health services. This is reinforced by the recognition that the POMR has almost equalized across high- and low-income nations worldwide with improvements in surgical and anesthetic safety practices [17]. Like the WHO indicators, it also lacks detailed context for perioperative deaths, which limits its applicability in improving healthcare systems.

Two metrics for surgical care services have been proposed that are more specific: the cesarean section ratio (CSR) [18] and emergent hernia repair ratio (EHR) [19]. The CSR is the ratio of cesarean sections to the total operations performed at a site. Cesarean sections, particularly when emergent, are expected to be more common in areas where antenatal care is limited. Similarly, hernias may be treated electively if medical care is sought and provided in a timely manner, but may require emergent reduction in the setting of incarceration, obstruction, or strangulation. The EHR is the ratio of emergent to elective herniorrhaphies. A CSR $>0.2$ or an EHR $>0.1$ is thought to represent a setting with critical medical access and surgical care deficiencies [20]. 
The EHR and CSR are not only strong in their ability to reflect access to available care, but are also equally applicable to both high- and low-income settings since hernia repairs and cesarean sections are performed worldwide in primary and tertiary medical centers by both physicians and physician-extenders. However, the EHR and CSR have limitations. Cesarean sections reflect women's access to obstetric care and ignore sizeable segment of the population, particularly the pediatric and male populations. Furthermore, increases in median maternal age in high-income countries, which reflect population changes rather than changes in access to care, could affect the CSR [21, 22]; CSR is therefore not generalizable globally. The EHR is also overly narrow in its focus and does not measure patients' access to available care for injuries, abdominal sepsis, obstetrics, or infectious processes.

There are several limitations to our study. First, the Ee ratio requires further validation before its use. Any metric is restricted by the available data, and despite completing a systematic search, publication bias still affects the type and scope of available data. A target Ee ratio should be developed through examination of comprehensive national surgical datasets created and contributed with this purpose in mind. Second, the Ee ratio makes no allowances for illness severity, surgical case complexity, or the quality metrics of care. While this is a trade-off made for generalizability, the Ee ratio must be used and interpreted with restraint. Our international and regional data also include a disproportionate number of citations from high-income countries, while data from low-income nations were predominantly at the hospital level. This heterogeneity likely hindered the ability to identify an independent association between physician workforce or GDP and the Ee ratio, and further validation of the Ee ratio may be pursued with the contribution of additional large datasets from around the world. In particular, this highlights the need for more investment in the development of national surgical registries from low-resource areas.

The Ee ratio is a simple and valid measurement of surgical access, availability, and capacity in healthcare systems, which can be applied with equanimity worldwide.
Improving access to safe surgical care is essential to any healthcare system. The provision of even basic surgical care has the potential to avert a large proportion of preventable morbidity and mortality associated with emergency surgery, and investments need not be costly or complex [7]. Surgical care is increasingly a priority for national and international health policy organizations, and the Ee ratio may serve as a useful metric to benchmark global improvements in the access and provision of surgical care.

Acknowledgements This study was supported in part by the National Institute of Health Fogarty International Center Postdoctoral Research Fellowship to Dr. Prin and by Grant 1 R49 CE002096 from the National Center for Injury Prevention and Control, Centers for Disease Control and Prevention to the Center for Injury Epidemiology and Prevention at Columbia University Medical Center. The contents of the manuscript are solely the responsibility of the authors and do not necessarily reflect the official views of the funding agencies.

Author's contribution MP and AC conceived of the study and performed the search strategy. MP and JG performed the statistical analyses. MP wrote the first draft of the report with input from AC, GL, OM, and JG. The final manuscript was approved by all authors.

\section{Compliance with ethical standards}

Conflict of interest We declare no competing interests.

\section{Appendix 1: search string}

("surgery"[title] OR "perioperative"[title] OR "surgical"[title] OR "operation"[title]) AND ("statistics"[title] OR "capacity"[title] OR "outcomes"[title] OR "data"[title] OR "management"[title]) AND ("national"[title] OR "regional" [title] OR "project"[title] OR "projects"[title] OR "hospital”[title] OR "survey”[title]).

Appendix 2: study search selection flow chart 


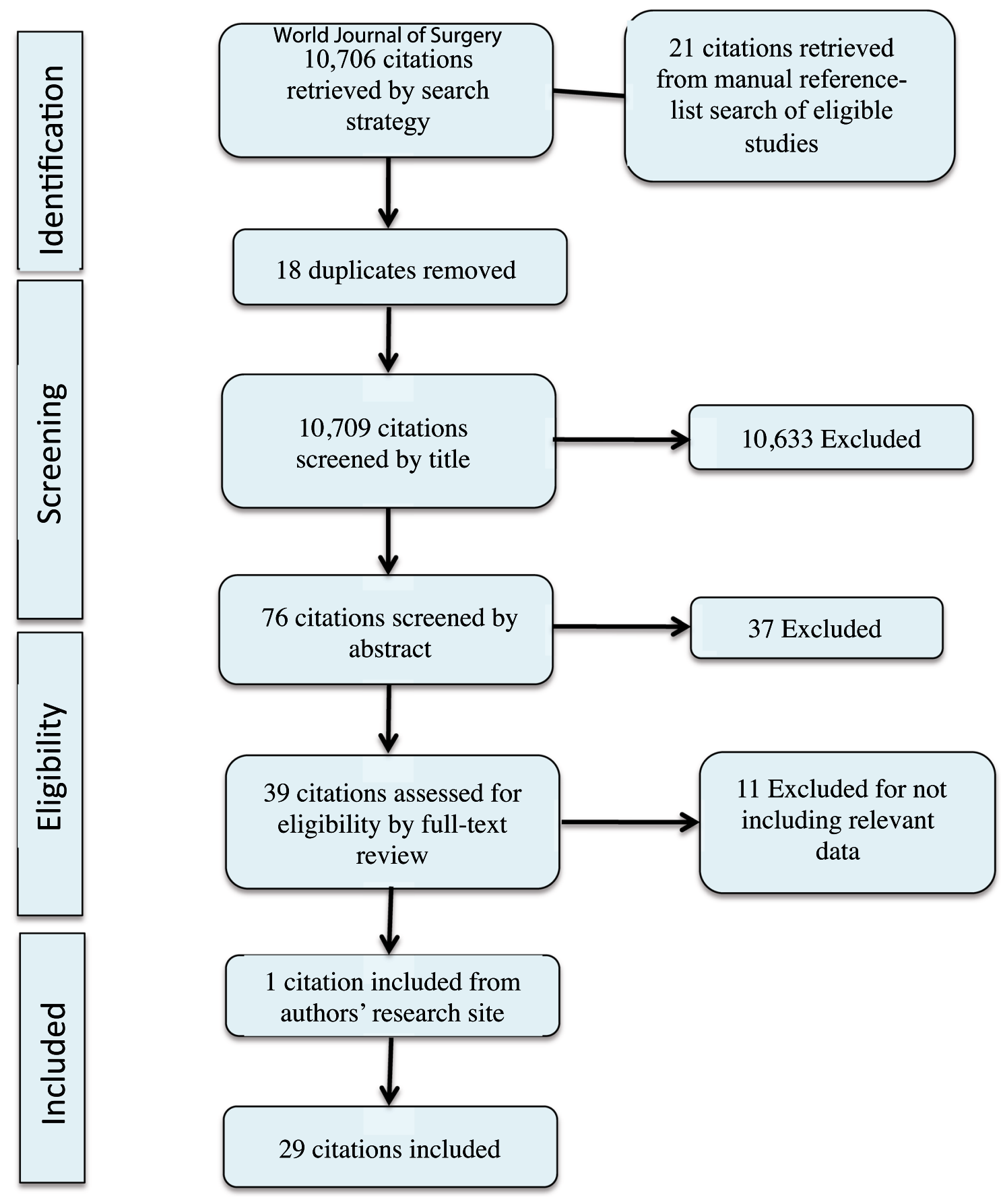

\section{References}

1. Meara JG, Leather AJ, Hagander L et al (2016) Global Surgery 2030: evidence and solutions for achieving health, welfare, and economic development. Int J Obstet Anesth 25:75-78

2. Long C, Titus Ngwa Tagang E, Popat RA et al (2015) Factors associated with delays to surgical presentation in North-West Cameroon. Surgery 158:756-763

3. Pacagnella RC, Cecatti JG, Parpinelli MA et al (2014) Delays in receiving obstetric care and poor maternal outcomes: results from a national multicentre cross-sectional study. BMC Pregnancy Childbirth 14:159

4. Hang HM, Byass P (2009) Difficulties in getting treatment for injuries in rural Vietnam. Public Health 123:58-65

5. Grimes CE, Bowman KG, Dodgion CM et al (2011) Systematic review of barriers to surgical care in low-income and middleincome countries. World J Surg 35:941-950. https://doi.org/10. 1007/s00268-011-1010-1

6. Lozano R, Naghavi M, Foreman K et al (2012) Global and regional mortality from 235 causes of death for 20 age groups in 1990 and 2010: a systematic analysis for the Global Burden of Disease Study 2010. Lancet 380:2095-2128 
7. Higashi H, Barendregt JJ, Kassebaum NJ et al (2015) Burden of injuries avertable by a basic surgical package in low- and middleincome regions: a systematic analysis from the Global Burden of Disease 2010 Study. World J Surg 39:1-9. https://doi.org/10. 1007/s00268-014-2685-x

8. Rose J, Weiser TG, Hider P et al (2015) Estimated need for surgery worldwide based on prevalence of diseases: a modelling strategy for the WHO Global Health Estimate. Lancet Glob Health 3(Suppl 2):S13-S20

9. Tansley G, Stewart BT, Gyedu A et al (2016) The correlation between poverty and access to essential surgical care in Ghana: a geospatial analysis. World J Surg. https://doi.org/10.1007/ s00268-016-3765-x

10. Thind A, Mock C, Gosselin RA et al (2012) Surgical epidemiology: a call for action. Bull World Health Organ 90:239-240

11. Weiser TG, Makary MA, Haynes AB et al (2009) Standardised metrics for global surgical surveillance. Lancet 374:1113-1117

12. Glance LG, Lustik SJ, Hannan EL et al (2012) The surgical mortality probability model: derivation and validation of a simple risk prediction rule for noncardiac surgery. Ann Surg 255:696-702

13. Whitlock EL, Feiner JR, Chen LL (2015) Perioperative mortality, 2010 to 2014: a retrospective cohort study using the National Anesthesia Clinical Outcomes Registry. Anesthesiology 123:1312-1321

14. Davies JF, Lenglet A, van Wijhe M et al (2016) Perioperative mortality: analysis of 3 years of operative data across 7 general surgical projects of Medecins Sans Frontieres in Democratic Republic of Congo, Central African Republic, and South Sudan. Surgery 159:1269-1278

15. Moher D, Liberati A, Tetzlaff J et al (2009) Preferred reporting items for systematic reviews and meta-analyses: the PRISMA statement. BMJ 339:b2535

16. Chu K, Rosseel P, Gielis P et al (2009) Surgical task shifting in sub-Saharan Africa. PLoS Med 6:e1000078

17. Watters DA, Hollands MJ, Gruen RL et al (2015) Perioperative mortality rate (POMR): a global indicator of access to safe surgery and anaesthesia. World J Surg 39:856-864. https://doi.org/ 10.1007/s00268-014-2638-4

18. Hughes CD, McClain CD, Hagander L et al (2013) Ratio of cesarean deliveries to total operations and surgeon nationality are potential proxies for surgical capacity in central Haiti. World $\mathbf{J}$ Surg 37:1526-1529. https://doi.org/10.1007/s00268-012-1794-7

19. Samuel JC, Tyson AF, Mabedi C et al (2014) Development of a ratio of emergent to total hernia repairs as a surgical capacity metric. Int J Surg 12:906-911

20. Stewart B, Wong E, Papillon-Smith J et al (2015) An analysis of cesarean section and emergency hernia ratios as markers of surgical capacity in low-income countries affected by humanitarian emergencies from 2008-2014 at Médecins sans Frontières Operations Centre Brussels Projects. PLoS Curr Disas. https://doi.org/10. 1371/currents.dis.5e30807568eaad09a3e23282ddb41da6

21. Yoshioka-Maeda K, Ota E, Ganchimeg T et al (2016) Caesarean section by maternal age group among singleton deliveries and primiparous Japanese women: a secondary analysis of the WHO Global Survey on Maternal and Perinatal Health. BMC Pregnancy Childbirth 16:39

22. Herstad L, Klungsoyr K, Skjaerven R et al (2015) Maternal age and emergency operative deliveries at term: a population-based registry study among low-risk primiparous women. BJOG 122:1642-1651

23. Pearse RM, Moreno RP, Bauer P et al (2012) Mortality after surgery in Europe: a 7 day cohort study. Lancet 380:1059-1065

24. AIHW (2015) Admitted patient care 2013-14: Australian hospital statistics. Health services series 60 no. HSE 156
25. Kjaergaard J, Bay-Nielsen M, Kehlet H (2010) Mortality following emergency groin hernia surgery in Denmark. Hernia 14:351-355

26. Nilsson H, Stylianidis G, Haapamaki M et al (2007) Mortality after groin hernia surgery. Ann Surg 245:656-660

27. Lundstrom KJ, Sandblom G, Smedberg S et al (2012) Risk factors for complications in groin hernia surgery: a national register study. Ann Surg 255:784-788

28. AbuSalah AM, Melton GB, Adam TJ (2012) Patient-specific surgical outcomes assessment using population-based data analysis for risk model development. In: AMIA Annual Symposium Proceedings 2012, pp 1089-1098

29. Ingraham AM, Cohen ME, Raval MV et al (2011) Comparison of hospital performance in emergency versus elective general surgery operations at 198 hospitals. J Am Coll Surg 212(20-28):e1

30. Guillamondegui OD, Gunter OL, Hines L et al (2012) Using the national surgical quality improvement program and the Tennessee surgical quality collaborative to improve surgical outcomes. J Am Coll Surg 214:709-714

31. Velanovich V, Shadduck P, Khaitan L et al (2006) Analysis of the SAGES outcomes initiative groin hernia database. Surg Endosc 20:191-198

32. Ansaloni L, Coccolini F, Fortuna D et al (2014) Assessment of 126,913 inguinal hernia repairs in the Emilia-Romagna region of Italy: analysis of 10 years. Hernia 18:261-267

33. Biccard BM, Madiba TE (2015) The South African surgical outcomes study: a 7-day prospective observational cohort study. S Afr Med J 105:465-475

34. Smith M, Hussain A, Xiao J et al (2013) The importance of improving the quality of emergency surgery for a regional quality collaborative. Ann Surg 257:596-602

35. Hernandez-Irizarry R, Zendejas B, Ramirez T et al (2012) Trends in emergent inguinal hernia surgery in Olmsted County, MN: a population-based study. Hernia 16:397-403

36. Costa Ada S Jr., Leao LE, Novais MA et al (2015) An assessment of the quality indicators of operative and non-operative times in a public university hospital. Einstein 13:594-599

37. Ohene-Yeboah M, Abantanga F, Oppong J et al (2009) Some aspects of the epidemiology of external hernias in Kumasi, Ghana. Hernia 13:529-532

38. Shidara Y, Fujita Y, Fukunaga S et al (2016) In-hospital mortality after surgery: a retrospective cohort study in a Japanese university hospital. SpringerPlus 5:680

39. Prin M, Charles AG (2017) Perioperative mortality in Malawi (unpublished data)

40. Faierman MLA, Anderson JE, Assane A, Bendix P, Vaz F, Rose JA, Funzamo C, Bickler SW, Noormahomed EV (2015) Surgical patients travel longer distances than non-surgical patients to receive care at a rural hospital in Mozambique. Int Health 7:60-66

41. Muhirwa E, Habiyakare C, Hedt-Gauthier BL et al (2016) Nonobstetric surgical care at three rural district hospitals in Rwanda: more human capacity and surgical equipment may increase operative care. World J Surg 40:2109-2116. https://doi.org/10. 1007/s00268-016-3515-0

42. Koka R, Chima AM, Sampson JB et al (2016) Anesthesia practice and perioperative outcomes at two tertiary care hospitals in Freetown, Sierra Leone. Anesth Analg 123:213-227

43. Mabula JB, Chalya PL (2012) Surgical management of inguinal hernias at Bugando Medical Centre in northwestern Tanzania: our experiences in a resource-limited setting. BMC Res Notes 5: 585

44. Akinci M, Ergul Z, Kulah B et al (2010) Risk factors related with unfavorable outcomes in groin hernia repairs. Hernia 14:489-493 
45. Lofgren J, Kadobera D, Forsberg BC et al (2015) Surgery in district hospitals in rural Uganda-indications, interventions, and outcomes. Lancet 385(Suppl 2):S18

46. Tumusiime G, Was A, Preston MA et al (2016) The quality and utility of surgical and anesthetic data at a Ugandan Regional Referral Hospital. World J Surg. https://doi.org/10.1007/s00268016-3714-8
47. Tiernan JP, Katsarelis H, Garner JP et al (2010) Excellent outcomes after emergency groin hernia repair. Hernia 14:485-488

48. Abi-Haidar Y, Sanchez V, Itani KM (2011) Risk factors and outcomes of acute versus elective groin hernia surgery. J Am Coll Surg 213:363-369 